\title{
Reflexiones sobre la luz y sus refracciones en la plástica de la era tecnológica. Del engaño visual de Federico Miró a la pintura 'encendida' de Alejandro Martín
}

Reflections on light and its refractions in the plastic of the technological era. From the visual deception of Federico Miró to the painting 'lit' by Alejandro Martín

Javier González Torres

Fundación Victoria - Universidad de Málaga. España (javier.gonzalez@fundacionvictoria.edu.es)

Recibido el 15 de junio de 2017; revisado el 10 de julio de 2017; aceptado el 18 de julio de 2017; publicado el 01 de septiembre de 2017

RESUMEN: La extraordinaria capacidad de 'reinvención' que la pintura está desarrollando en las últimas décadas permite afirmar su plena vitalidad: un interesante proceso de redefinición que se proyecta en parámetros intrínsecos al lenguaje pictórico o en otros hasta ahora poco tratados, proporcionando al resultado final pluralidad, matices, polisemia y pertinencia. Potencialidades que han de ponerse en relación con la era tecnológica actual, contaminada por recursos cibernéticos, digitales y fotográficos. Dos artistas noveles, Federico Miró y Alejandro Martín, plantean en sus indagaciones plásticas un giro de tuerca al fascinante mundo de la creación pictórica. El estudio de propuestas históricas les lleva en cada caso a descubrir individualmente nuevos caminos que bordean lo figurativo y lo abstracto, con puntos en común pero también con notables divergencias. Y la luz, siempre la luz, actuando de sugestivo vehículo para concretizar imágenes o comprobar de qué manera su proyección y reflejo sobre determinados elementos pueden ser objeto de nuevas percepciones.

PALABRAS CLAVE: Pintura, era tecnológica, arte emergente, engaño visual, pintura encendida.

\footnotetext{
ABSTRACT:The extraordinary capacity of 'reinvention' that the painting is developing in the last decades allow to affirm its full vitality: an interesting process of redefinition that is projected in parameters intrinsic to the pictorial language or in others until now little treated, providing the final result plurality, nuances, polysemy and pertinence. These potentialities must be related to the current Technological Age, contaminated by cybernetic, digital and photographic resources. Two emerging artists, Federico Miró and Alejandro Martín, pose in their plastic inquiries a twist to the fascinating world of pictorial creation. The study of historical proposals leads them in each case to discover new paths that border the figurative and the abstract, with points in common but also with notable
} 
divergences. And the light acting as a suggestive vehicle to concretize images or check how their projection and reflection on certain elements can be the object of new perceptions.

KEYWORDS: Paint, Technology Age, emerging artists, visual deception, painting 'on'

Un concepto genérico de pintura la define como aquella respuesta plástico-emocional de un autor imbuido, en unas circunstancias particulares y un tiempo concreto. Desde las primeras grafías impresas por los homínidos, se han sucedido culturas que han ejercido sus influencias a través del grafismo, los pigmentos, los aglutinantes y los secativos, el color y el dibujo. Y hoy, en esta sociológica 'modernidad líquida' o 'sociedad del riesgo' que vivimos, en plena era tecno-digital, la disciplina pictórica sigue viva.

Algunos se habían encargado de 'matarla' a finales de los años 80. Pero al igual que los héroes de la antigüedad, la pintura renace hoy sobre sus cenizas, reinventándose y adaptándose a las circunstancias. En la búsqueda de nuevos estímulos aparecen experimentaciones sobre materias innovadoras, imágenes novedosas, técnicas distintas, procesos científicos hasta ahora desconocidos, reproducciones mecánicas insospechadas o aspectos electrónicos procedentes de flamantes investigaciones. La fusión de métodos, formas, preceptos y reglas conducen a la configuración de nuevas propuestas que recorren sugerentes caminos expresivos en los que la libertad individual y la propia evolución e interés del artista juegan un papel crucial.

Sin embargo, 'no todo el monte es orégano'. A veces, el debate está más bien en descifrar si una determinada propuesta consigue mostrar algo fresco, nuevo. La consabida fórmula en la que al valor cultural heredado se le suma la necesaria comunicación que debe establecerse con el espectador, abre un camino donde lo críptico y, a veces, lo incomprensible o discordante, termina tergiversando el concepto artístico y desfigura, diluye e incluso banaliza el mensaje final. El impacto no siempre es positivo ni, mucho menos, el esperado, aunque en la génesis del proyecto el creador trate de desconcertar los sentidos y las emociones del que verá la obra, presentándose como un manipulador de la modernidad, un baluarte radical de lo novedoso, un trasgresor revolucionario o un super-star de la progresía de las artes visuales. En este sentido, no todo vale. La pintura no es, ni debe ser, un espectáculo más propio del entretenimiento que del placer estético. Para eso ya están otros. 
Es cierto que el arte emergente de este segundo milenio que comenzamos a vivir parece sustentarse a veces sobre cimientos con aluminosis. La degradación y pérdida de resistencia que alteran algunas estructuras visuales, provocan grietas y hacen saltar algunas alarmas que preconizan un empobrecimiento de la creatividad y la genialidad. Nuestro tiempo está en consonancia con la globalización mundial y la realidad del arte y de todo cuanto a éste rodea; somos partícipes de un período de transformación, de reformulación, que abarca múltiples planos. De ahí la existencia de un criterio ambiguo, ecléctico, cuando no 'anestesiado' por los poderes fácticos o por los capciosos criterios procedentes de los 'totalitarismos' pseudo-culturales, donde la vanidad personal y la espontaneidad artística apenas si dejan entrever un puñado de habilidades técnicas insertas en un conjunto heterogéneo y diverso. En éste hay de todo: desde experiencias conceptuales, muchas de ellas radicales, hasta el más elemental protagonismo del material, en un ejercicio de simplificación de conceptos y búsqueda de la esencialidad que ya se hizo antes. Y es así cómo se explica que la falta de asentamiento de propuestas que aporten ese plus novedoso lleve a algunos 'visionarios', profesionales del caos y defensores de lo mediocre, a presagiar otra cercana muerte para el arte, y, por ende, para la pintura.

Pero no está todo inventado. Hay necesidades que no se han cubierto y cauces, medios y formas latentes que requieren -necesitan incluso- ser experimentadas, argumentadas y desarrolladas. De ahí que los artistas actuales deban tomar conciencia del papel a asumir. No se trata solo de una 'emergencia' expresiva, sino de plasmar una posición militante -pero no política-, favorable a 'construir' una obra donde la seducción y la persuasión, inherente a todo arte visual, produzca en el espectador un fascinante deleite que le obligue a examinar el producto con detenimiento, atrayendo su atención a partir de estímulos que cautiven su ánimo y lo conduzcan a visiones renovadas del mundo.

Un camino que no es fácil y en el que deben tenerse también en cuenta distintas precauciones. En la libertad expresiva del artista, éste no debe caer en una fiebre comunicativa con tal que el espectador se convierta en irreverente cómplice de un producto extraño. La sociedad de la comunicación, en la que los media y la espiral consumista proyectan también sus luces y sus sombras sobre el universo de la creación artística, ponen en cuestión las posibilidades del arte emergente, tergiversando su función al apostar por subproductos de épocas anteriores que copan museos creados ex profeso, galerías de parciales líneas expositivas o circuitos oficiales donde los proyectos públicos buscan antes el resultado mercadotécnico que la trascendencia artística; o, cuando por el contrario, suelen defenderse propuestas que, aun siendo actuales en su factura, no aportan nada al ser en su esencia hijastras edulcoradas de conceptos trasnochados. Incluso en un mundo tan tecnificado, 
tendente a etiquetar cualquier cosa como si fuese otra lucha por alcanzar la fama efímera del trendic topic, hay quien busca dotar este proceder 'inoculado' con el nombre de algún síndrome extraño, producto de un mal sueño, trastorno disociativo o amnesia temporal.

El confuso término de 'lo contemporáneo' aplicado al arte no es más que otro 'mantra' bajo el que se agrupan trabajos fragmentados de efervescentes artistas que dan muestras de una cuantiosa actividad pictórica y que hacen multiplicar exponencialmente tímidas tendencias encauzadas por pretenciosos modos, bautizados incluso como nuevos 'ismos'. Préstamos y contaminaciones que son el resultado de la interacción global de disciplinas que en ocasiones llegan a destruir los parámetros acostumbrados de las tradicionales, subsumidas bajo los presupuestos más en boga, acusadas de ocasionar adiciones perniciosas o masificar el universo artístico hasta llegar al hastío.

Otra de esas tergiversaciones llega a través de la banalización de los procedimientos expresivos y de una mal entendida democratización de la agilidad, la destreza y la vocación por el arte. La crisis que tan gravemente aún azota al mundo ha cercenado la vitalidad de la propia creación artística. La mediocridad, la repetitiva puesta en escena de modelos caducos, la débil formación academicista ofrecida por centros que años antes eran referentes y hoy están más preocupados de subsistir ante el cierre de los grifos financiadores o, entre múltiples cuestiones, el torpe convencimiento autodidacta de quienes, de la noche a la mañana se consideran 'artistas inigualables', provocan que cada vez más el producto quede relegado a espejismos o a perversiones que confunden a un espectador que adolece igualmente de una formación cultural que le permita distinguir -dentro del abundante adocenamiento artístico- lo que es novedoso de lo que, por desgracia, no lo es. A ello también ha contribuido la 'desacralización' de los procesos, técnicas, métodos, usos, materiales, experimentaciones y calidades finales de la producción artística, vulgarizadas hasta extremos que con un simple tutorial subido a la red pierden su sentido para convertirse en hobbies con los que pasar una 'divertida tarde de domingo'.

Escudriñar los resultados de esa ingente producción, quizás en la época más productiva del arte y sus subproductos, no es tarea fácil. Tal masificación global, con independencia de su validez o no, puede provocar a su vez efectos contraproducentes para la esencia misma de los mecanismos plásticos y audiovisuales. La espesa niebla que se cierne sobre este trascendental hecho debiera dar paso a 'claros entre nubes' que señalen vías nuevas. Existir, existen. Aunque no son sencillas de explorar, investigar, desarrollar, proponer, convencer... Se trata de los artistas del siglo XXI y no de los ya consagrados, descendientes o supervivientes de la centuria anterior. A ellos y a su actividad habrá que 
dedicarles tiempo y estar muy atentos, aunque esta labor, por minuciosa, sea como aquello de buscar una aguja en un pajar.

\section{La luz y sus refracciones en la plástica actual: la aportación de dos jóvenes creadores}

Las extraordinarias posibilidades que la propia pintura ofrece desde que las Vanguardias históricas pusieron en valor l'art pour l'art, siguen siendo hoy motivo de investigación. La extraordinaria capacidad de 'reinvención' que la propia disciplina desarrolla cuando la cosa no 'pinta bien', hizo que el acta de defunción antes mencionada no llegara a firmarse: las estrategias de regeneración anduvieron prestas a socorrerla de la debacle.

$\mathrm{Y}$ es que, desde esa decadencia preconizada hasta ahora, puede advertirse un interesante proceso de redefinición que se proyecta en parámetros intrínsecos al lenguaje pictórico o en otros hasta ahora poco tratados, proporcionando pluralidad, matices, polisemia y pertinencia al resultado final. Esas potencialidades han de ponerse en relación con la era tecnológica actual, contaminada por recursos cibernéticos, digitales y fotográficos. Todos han salido al rescate de la pintura en una estratégica mixtificación de las artes y correlación de fuerzas que no es novedosa, aunque sí sintomática por el diferente origen de las mismas. El resultado es una propuesta cuya base fundamental es la pintura, que amplía y completa su discurso con hibridaciones y mestizajes tomados de esos otros medios. Se configura así un novedoso universo que permite vislumbrar, sin ambages y a fuerza de no ser conclusivos por el estado iniciático de su gestación, interesantes resultados.

En este sentido y desde varios frentes, se advierte de la existencia en España de una generación que, nacida en los albores del siglo XXI, trata de reflexionar sobre esta cuestión; es decir, que indaga en ese proceso de 'contaminación no abrasiva' por los que 'camina' la pintura actual, haciendo de esta mixtura su propia razón de ser. En esa capacidad de reinventarse, una extensa pléyade de creadores trabaja en registros figurativos, relatos y narraciones, autorreferencialidad y objetualidad a partir de estrategias, enfoques y materiales menos acostumbrados, convidando a los pigmentos a un viaje espacial que va más allá de los límites físicos del plano o del soporte. En un intento de establecer incluso una clasificación tipológica y referencial, conocidas firmas tratan de poner el acento en estas propuestas, estudiando sus influencias, así como los recursos, herramientas y procesos llevados a cabo.

De esas propuestas y tensando algo el discurso -con la idea de establecer un posible denominador común entre ellas-, puede apreciarse en muchas de ellas el desarrollo de un lenguaje que 
tiende hacia una 'abstracción narrativa'. Este complejo concepto permite que, bajo la superficie trabajada de la tela, se argumenten historias específicas, subjetivas, que exteriorizan una experiencia íntima sin pretensiones de ser etiquetada en catálogo alguno. El objetivo a cumplir es el de canalizar plásticamente una vivencia particular que camina sobre pasos firmes entre la observación trivial y una percepción sofisticada. Y centrados en esta situación, surge en el seno de esta nueva generación de artistas plásticos otro debate interesante: el de la luz.

Que duda cabe que, en ese proceso de repensarse a sí misma, la pintura no podía dejar de lado uno de sus principales pilares plásticos que no sucumbió, junto al color, al premeditado ‘asesinato' de la perspectiva de base matemática que perpetraron las Vanguardias y al ocaso que por consiguiente experimentaron, por artificiosas, las técnicas de representación tradicional. En la esencialidad y pureza de la materia pictórica -génesis del nuevo arte de las primeras décadas del siglo $\mathrm{XX}$-, las refracciones de la luz y las tonalidades descuellan como elementos esenciales sobre los que se 'proyectan' las poéticas de la modernidad, condicionando indefectiblemente tanto el resultado final como la percepción que de la obra haga el espectador. Y es que, en efecto y en su carácter más intrínseco, la problemática de la luz ofrecía así un amplio campo de 'retorno' a procesos refractivos básicos a los que se añadían, por entonces, los avances científicos que argumentaron propuestas sobre la naturaleza de las luces y la teoría del color. Abandonado el campo iluminante, espectral y teatralizador de épocas pretéritas, los caminos a explorar se multiplicaron a lo largo de toda la centuria a la par que las propuestas, tendentes a plasmar sensaciones visuales e ilusiones ópticas donde lo cambiante y lo dinámico interaccionan entre sí.

De todos ellos y atendiendo a los criterios de correlación con el entorno cotidiano, el estudio que en la actualidad se hace sobre la luz debe relacionarse con una premisa básica: la saturación de imágenes provocada por los medios digitales, el ciberespacio, la televisión, el cine o los videojuegos. El asequible precio de dispositivos móviles cada vez más sofisticados y con mayores prestaciones o la invasión del espacio urbano por parte de monumentales pantallas, son ejemplo de una evidencia que no pasa desapercibida. E incluso existe una consecuencia más: el usuario de estas imágenes, en especial las proyectadas por las redes sociales o las captadas a través de la óptica de un smartphone o terminal similar, no solo es 'consumidor' o 'usuario' sino que, siguiendo sencillos y automáticos pasos, se convierte sin esfuerzo en 'creador' y 'editor'.

Ambos planteamientos, con sus correspondientes acciones, pueden terminar arrinconando a la pintura a la esquina más alejada del discurso crítico. Pero ante tan hipócrita como fácil farsa, el mundo 
de la creación sigue apostando - iy menos mal! -, por otorgar de significación, interpretación y lectura el análisis de la luz, así como su proyección y ejercicio en obras de arte. De hecho, hoy por hoy, es un tema objeto de estudio de disciplinas distintas, por cuanto su aplicación en la vida doméstica contiene lógicas repercusiones en el terreno artístico. La psicología vinculada a las áreas de confort, las posibilidades de reflexión y absorción que determinan el comportamiento de materiales y colores, la descomposición, fugas visuales, recomposición y texturas que consiguen 'modelar' formas a partir de volúmenes o, simplemente, las motivaciones sensitivas que son capaces de generar estados de ánimo concretos son, en suma, algunas de esas vías.

Para los pintores emergentes, la luz per se es un elemento fundamental de la narración construida; otorga matices dinámicos al erigirse en agente activo de la configuración del espacio y en la creación ambiental, relacionándose justamente con esos principios anteriormente expuestos por los que camina la investigación. El resultado es de nuevo híbrido, como lo son las influencias digitales de las que se nutre, desdibujando los límites entre lo real y lo virtual, para crear propuestas enraizadas en el contexto tecnológico y del todo diferenciadas de las heredadas del siglo XX.

Es ese punto de 'realidad cotidiana' uno de sus aspectos más contundentes. Además, es el que comparten los jóvenes Federico Miró Jurado y Alejandro Martín Romero (ambos nacidos en Málaga, en 1991). Formados al amparo de la Facultad de Bellas Artes de la Universitas Malacitana, complementados con Máster en la Complutense de Madrid y en el propio centro docente de origen respectivamente, plantean en sus indagaciones plásticas un giro de tuerca al fascinante mundo de la creación pictórica. El estudio de propuestas históricas les lleva en cada caso a descubrir individualmente nuevos caminos que bordean lo figurativo y lo abstracto, con puntos en común pero también con notables divergencias. Y la luz, siempre la luz, actuando de sugestivo vehículo para concretizar imágenes o comprobar de qué manera su proyección y reflejo sobre determinados elementos siguen siendo objeto de nuevas percepciones. Estos artistas han llegado para sumarse a esa corriente defensora de la materia pictórica, de su vitalidad y funcionalidad, aportando experiencias y opiniones que deberán ser tenidas en cuenta.

\section{El engaño visual de Federico Miró}

El 'estiramiento' de la capacidad expresiva de la pintura como parte del proceso que permite a la naturaleza cambiar de estado; la lucha entre lo reconocible y lo desconocido, plasmado a través de un particular código gráfico que no permite delimitar de manera clara los linderos entre lo uno y lo otro... 
Esa es la actitud que la labor de este artista provoca: una doble lectura final de lienzos donde la propia visión queda secuestrada por el gozo estético.

El proceso en sí muestra a su vez rasgos de hibridación. Las posibilidades tecnológicas otorgan al producto, en la distancia, un aspecto primario digital; pero éste acaba siendo, a medida que aproximas la mirada al soporte, netamente pictórico en su ejecución y apariencia. La laboriosidad de esta última fase, más propia de la paciente elaboración con la que los monjes del medievo 'iluminaban' los manuscritos, es del todo sugerente $\mathrm{y}$, por supuesto, contrapuesta a los actuales términos de inmediatez o velocidad que aportan otros procesos mecánicos y/o automáticos.

Los motivos que se reflejan en estos lienzos son parte misma de la propia naturaleza. El fin no es otro que reflexionar acerca de los límites de la pintura y su capacidad para configurar imágenes dotadas de un sentido distinto, con múltiples interpretaciones. No se trata de reproducir siguiendo los criterios miméticos renacentistas; muy al contrario, la apuesta se traslada al propio entorno de la sugestiva representación, al motivo mismo y principal de la obra, al que Miró hace culpable de ser capaz de 'revelarse' ante el espectador.

La naturaleza vive en la propuesta de este artista en un reto constante: un proceso de descubrimiento frontal a partir de la aplicación de esas líneas horizontales que 'cruzan' los laterales del lienzo, jugando con ritmos, tonos y vacíos. Se trata de una trama codificada, un medio indómito que, cual filtro, hace que las referencias figurativas se camuflen bajo una apariencia misteriosa. Es una 'llamada' al espectador de modo que su mirada actúe de vía para preguntarle a la psique qué entiende y qué es aquello que no logra descifrar. Naturaleza frente a razón. El espejo de lo real -tamizado por un velo de cierta opacidad - frente a la contradictoria naturalidad de la mente humana, presta a recomponer y dotar de sentido a aquello que parece entender a simple vista.

Esa pugna remite a planteamientos básicos, propios de la disciplina pictórica: ¿dónde se encuentran los límites entre la figuración y la abstracción? La cercanía de la primera no es más que una sutil veladura que enmaraña una realidad tendente a lo abstracto. Sin embargo, Miró no utiliza los cauces expresivos que el Surrealismo y otras propuestas ya indagaron. En sus obras, lo abstracto adquiere forma, casi se concretiza, dejándose 'seducir' por la todopoderosa fuerza de la imagen. Unas sensaciones que igualmente han sido puestas en valor por otros artistas, a los que el propio Federico Miró alude de manera sutil. En este sentido, destaca con especial fuerza el recuerdo al medio natural latente que Javier Garcerá, profesor y creador plástico de referencia en la actualidad, 'metamorfosea' 
en sus lienzos a partir de un ejercicio en el que prima lo fenomenológico y lo perceptivo (Garcerá, 2009: s/p).

En ese sentido, el proceso que termina gestando la propuesta de Miró viene de lejos. Estando en el tercer curso del grado académico, cae en sus manos una ecografía. Desligada de cuestiones puramente científicas, al entonces estudiante le llama poderosamente la atención la textura de esa imagen que, aun estando presente y siendo artificial en su reproducción, necesita de una oportuna y 'experta' explicación que haga comprender su total significado. A partir de ello y profundizando sobre esos -a primera vista- indescifrables límites, comienza una particular experimentación: buscando un mayor sentido, lo contrasta con el paisaje a partir de barridos, de capas de acrílico que actúan cual veladuras superpuestas sobre el acetato1.

Un período de ensayo-error en el que además el autor trata de no caer en tentativas anteriores. Su capacidad analítica y deseo de conocimiento le lleva a descartar otro tipo de trabajos, como los planteados en su momento por Dubuffet, avanzando más hacia una idea no premeditada. Pero los resultados no permitían apenas ningún avance, pues la opacidad del acrílico apenas si lograba 'destapar' zonas reconocibles. Hasta que, finalmente, salió una pequeña línea en un barrido con la espátula. A partir de ahí, del estudio de esa escasa textura en pequeños formatos, el novel creador siguió con su singular e incluso artesanal proceder hasta convertirlo en principal leitmotiv de sus obras.

La codificación del mismo parte de un paso previo que también resulta esencial: la captura fotográfica de referentes naturales, paisajes fundamentalmente. Recopiladas esas imágenes y seleccionadas en función de un criterio estético, se pasa a la edición digital de la mismas -a partir de la fragmentación, la alteración del punto de vista o los reencuadres de la visión-, añadiéndose además una reducción cromática a dos o tres tonos elementales, primarios. El paso siguiente deja de lado, aparentemente, el mundo tecnológico para centrarse en lo pictórico pues, a partir de esa manipulación subjetiva, el resultado se traslada al lienzo.

Llegados a este punto, el proceso creativo está en la fase de máximo cuidado. Se hace lento, selectivo, minucioso. El dibujo, el formato y los tonos proceden del tratamiento digital. Sin embargo, la consecuencia plástica depende de las propias limitaciones del artista y de su capacidad por autoimponerse a sí mismo sus propias reglas que, incluso, no admiten error posible. La imagen y el fondo se mezclan, pierden sus límites formales y visuales. El lienzo es una inmensa 'plancha'

\footnotetext{
${ }^{1}$ Las afirmaciones que se recogen en este párrafo y siguientes sobre el proceso creativo empleado por Federico Miró, son fruto de una entrevista personal llevada a cabo en diciembre de 2016.
} 
bidimensional sobre la que el acrílico alcanza protagonismo absoluto. Sin embargo y bajo esa apariencia momentánea, el artista logra concretar los tonos primitivos en un ejercicio básico similar al de positivo-negativo. Es el instante en el que se procede a 'rayar' el soporte mediante líneas horizontales, de izquierda a derecha, paralelas, firmes, milimétricamente trazadas. Al día siguiente y una vez seca la materia, el artista procede a aplicar en determinadas zonas una nueva capa, 'barriendo' a su vez la pintura de otras áreas en la que sí subsisten los referentes figurativos. Es de esta manera como, poco a poco, van saliendo a la luz los motivos que al principio dieron sentido a la composición a partir de una estudiada elección de colores.

La doble lectura final, a la que ya se ha aludido, es del todo sugestiva. Las obras de Miró requieren ser vistas en la distancia, estableciendo con ellas un espacio físico suficiente donde la percepción visual se encarga de conectar elementos y concretar una imagen formal, aunque no nítida. Es en ese terreno donde el sentido y significado de la propuesta adquiere rasgos estéticos, similares en sus primeras obras a asimétricos paisajes naturales y, en las últimas, a tapices textiles, ordenados a partir de un eje vertical, en donde la forma vegetal evoca a aquellos roleos de grutescos que en pleno siglo XVI fueron descubiertos en la Domus Aurea de Nerón [1].
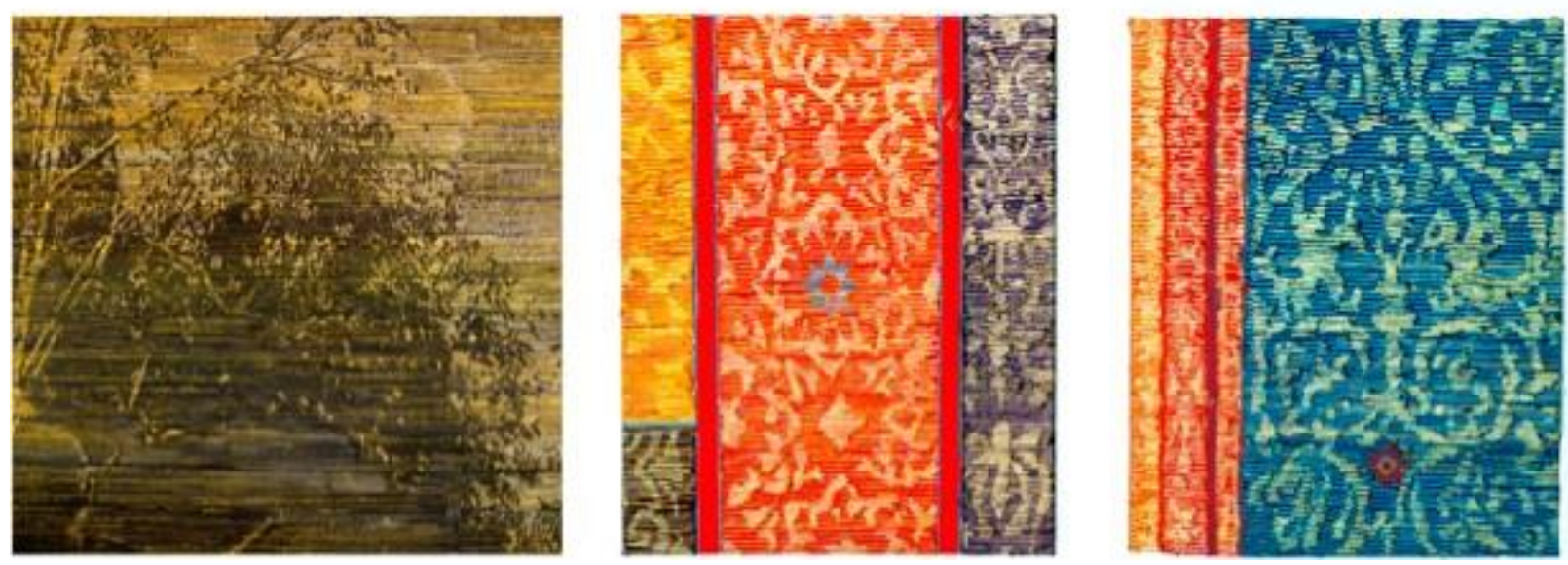

[Fig. 1] Federico Miró. Obras sin título pertenecientes a las series Hasta donde la mirada alcance (2013) y La densidad de la urdimbre (2016)

Es justamente en esa capacidad evocativa de estos lienzos, así como la diferente manera de percibirlos por parte del espectador, lo que ha llevado al artista al reconocimiento público2. Los productos galardonados proceden, en ocasiones, de estancias realizas entidades académicas de

\footnotetext{
${ }^{2}$ En su haber descuellan los premios de la beca de pintura de paisaje de la Academia segoviana de San Quirce y el del VII de pintura de la Universidad de Málaga (ambos de 2013); finalista en el Griffin Art Prize de Londres y la máxima distinción dada por el Salón de Verano de Madrid (2014); mención de la Fundación Focus-Abengoa y selección para el 30 premio BMW de pintura (2015); mención especial en el MálagaCrea y segundo puesto en XXI certamen de jóvenes pintores de la Fundación Gaceta, de Salamanca (2016).
} 
prestigio; de igual manera, su firma se ha convertido en habitual en exposiciones colectivas, alabando la crítica su capacidad creativa para proponer lienzos en los que, a partes iguales, se mezcla lo novedoso con una poderosa fuerza expresiva.

\section{La pintura 'encendida' de Alejandro Martín}

La sugestiva emisión de imágenes a partir de una pantalla retroiluminada ha captado la atención de Alejandro Martín. Su experimentación busca plasmar bajo una ilusión pictórica esa misma proyección. Se trata de una perversión que rivaliza entre la naturaleza del óleo -vuelta opaca por la continua superposición de veladuras- frente a un medio adverso, contrario, producto de la tecnología: la pantalla digital. La luz que emana desde la 'encendida' pantalla del ordenador y las múltiples percepciones que de ella hace el espectador, constituyen el punto de partida de un estudio mucho más profundo.

En su génesis, ese punto de partida se relaciona por completo con una particular reflexión teórica que, en todo momento, va a condicionar el producto final. Incluso en algunas ocasiones, la propia elaboración artística se complica en exceso por esos fundamentos conceptuales hasta el punto de llegar al bloqueo. Es así como la capacidad reflexiva queda unida a otras dos claves fundamentales: el interés por conocer cualquier opinión anterior con independencia de su origen y el desarrollo de un particular perfeccionismo, innato a la persona. Los tres aspectos resultan claves a la hora de aproximarse al trabajo de este artista.

Referenciadas esas tres líneas, que actúan al modo de complementos al espíritu creativo, el siguiente paso es buscar una imagen lo más 'abierta' posible; es decir, que no esté condicionada ni contaminada por prejuicios visuales ni contenga posibles valores simbólicos. Pero su elección no es baladí, ni tampoco rápida3. Centrado en el medio tecnológico, al navegar por la red, el artista aplica una mirada contemplativa. Él no es un flâneur cibernético; muy al contrario, Martín se interesa sobre todo la luz que reciben los cuerpos a través de las pantallas, un resplandor que es un juego de espejos similar a cuando una modelo se sitúa ante un escenario y se fotografía; la luz que ésta recibe, natural o artificial, se vuelve a proyectar sobre el mismo cuerpo, que la recepciona y la refleja. Esos haces luminosos de doble dirección implican, conceptual y sencillamente, una superposición de realidades. Terrenos distintos pero que se vuelven iguales al recibir y aportar matices, sensaciones y brillos.

\footnotetext{
${ }_{3}^{3}$ De igual manera que con el otro artista, el desarrollo del proceso creativo ideado por Martín fue puesto de manifiesto por éste en entrevista personal realizada en diciembre de 2016.
} 
No es sencillo pues, en ese rastreo previo, que la seducción por lo abstracto esté presente; la continua 'invitación' que ésta sugiere y la oportunidad de dejarse llevar por su universo informe de luces, es evidente. Pero el artista, aun siendo consciente de ello y fascinándole ese abanico de posibilidades, apuesta por mantener a toda costa una figuración mínima, reconocible. Para ello basta cosificar la forma a través de un objeto que lanza su sombra, se proyecta hacia el espacio y condiciona, en cierto modo, la percepción del espectador, al que trata de situar en un contexto físico determinado.

La referencia teórica vuelve a estar presente en el procedimiento que el artista aplica. La definición y defensa que Hito Steyerl - una simpar referente en el terreno del videoarte y el ensayo filosófico- hizo de la 'imagen pobre' subyace en esta fase (Steyerl, 2014, pp. 34). La alemana utiliza este concepto para referirse a aquellas constantes visuales que están presentes en los medios digitales, redes sociales y demás aplicaciones que conectan a través de un dispositivo a las personas con un mundo exterior. En esos productos, propios de una economía visual evidente, importa poco su calidad, nitidez o resolución; pero, por el contrario, son capaces de desarrollar una notable fuerza comunicativa. La transmisión fugaz, rápida y directa que ese catálogo 'residual' de imágenes es impactante. De hecho, llega a conseguir -influenciada por otras connotaciones propias del terreno de la publicidad y dotadas de una todopoderosa transmisión ideológica-, poner en jaque procesos más elaborados, propios de otros momentos históricos, rivalizando con éstos. Martín, siendo consciente de esa dualidad, intenta cabalgar por esos dos 'mundos', haciendo guiños a uno y otro pero sin caer en la banalización ni en una especial predilección ni por lo excesivamente culto ni, por el contrario, por lo más vulgar.

No obstante, la especulación estética que Alejandro Martín trata de desarrollar tiene miras más avanzadas. Influido por los estudios y las experimentaciones realizadas junto con otros compañeros, su selección de imágenes puede parecerse como a quien escoge al azar un corte de una película. Esa acción en sí supone congelar un instante, crear una falsa realidad, una 'ficción consciente'. He aquí la clave con la que juega el artista: entregar un mensaje reconocible en algunos de sus parámetros visuales, darlo a conocer a los demás a partir de una particular plasmación en el lienzo y provocar, finalmente, un mensaje nuevo, desligado de su origen pero dentro de una atmósfera creíble.

La imagen escogida se edita digitalmente, permutando sus cualidades lumínicas hacia una sutil línea de aberración cromática que, eso sí, no cortocircuite su futura comprensión. En la mente del artista está presente la premisa de mantener cierta asepsia icónica, como ya se ha comentado. La solución, en este sentido, viene de la mano de la fragmentación que acota de tal manera el punto de 
vista para que, aún dentro de un escenario figurativo, la limitación perceptiva de detalles cobre vida junto a ciertos rasgos abstractos.

Lo que la pantalla ofrece y la ilimitada función de la pintura. Ahí está el siguiente reto, que es el paso decisivo dentro de esta vía experimental. Para ello, Martín escoge el óleo como base técnica tradicional para la aplicación de su propuesta. Se trata de un material brillante que permite pintar sobre fresco, modular la pintura, retocar en una misma sesión hasta diez veces. El mismo artista se encarga de remarcar que, en los primeros pasos en los que el tratamiento digital se traspasa al lienzo, la mancha que surge está en un principio muy atada a la razón. Las pinceladas se vuelven demasiado automáticas, no tienen frescura y la mano del creativo se tensa. Sin embargo, lo interesante sucede minutos después en los que, cuando lleva tiempo trabajando en una imagen sin excederse en demasía, surge la plasmación de un espacio que abre puertas hacia otras fronteras. Se asemeja en cierto modo ese momento al de la libertad creativa de los dadaístas: al despojarse de ese subconsciente, de una norma canónica que ha quedado inerte o desconectada, el azar provoca la llegada de formas inesperadas, sorpresivas. Esas son las que pueden apreciarse en sus telas que, además, son paradójicas, puesto que la seducción que vivió el creativo cuando seleccionó la imagen en un principio ha dado paso a un resultado final que, aún partiendo de aquella, mantiene solo algunos rasgos iniciales. Se muestra ahora completamente distinta, más fresca y rápida, presta para que el espectador se implique en ella y la interprete en función de su criterio.

Es una especie de universo pictórico paralelo que guarda una íntima relación con la propia pantalla y cómo ésta también es capaz de transmitir una cosmología particular, alejada por completo de la realidad. Para Alejandro Martín, esa particularidad tiene un componente estético al interesarse por la refracción constante de la artificiosa luz que ofrece la pantalla del dispositivo al que se enfrenta esa persona y cómo ésta se proyecta sobre la propia piel, acortándose la distancia entre lo humano y lo tecnológico que termina por convertirse, como ya se dijo anteriormente, en un solo elemento: la pintura 'encendida'. Atrapados en la red no es solo una canción premonitoria de esa adicción transcultural que nos invade, sino también el pretexto para el estudio que el artista pretende llevar a cabo.

Esos reflejos se advierten en una serie que Martín Romero firma, en pequeño formato, sobre telas de algodón de grano medio, previamente imprimada, y que son el resultado de una estudiada búsqueda. Se tratan de fragmentos del cuerpo humano sobre los que tonalidades verdosas y aguamarinas tratan de convertirse en brillante capa que diluye formas concretas, situándolas más en el mundo de la animación. Una desnaturalización que, sin embargo, no es óbice para comprender que 
esos retales humanos se han convertido en reflejo de una realidad cibernética, cuyo espectro de luces se proyecta chocando con las carnaciones y el color propio de la piel. Las formas ganan protagonismo, en un claro ejercicio donde la sensualidad y el erotismo se hace presente sin ambages ni cortapisas, en una línea de abstracción narrativa clara. La mirada del espectador es la que debe reconstruir esas deslavazadas sensaciones cromáticas, tomando distancia física con los lienzos y siendo capaz de asumir su papel como intérprete del mensaje final.

La similitud formal con otras propuestas coetáneas, como la de Johannes Kahrs para la serie de 2002 titulada Dirty pictures, es evidente. Del alemán también intuye Martín su capacidad para optar por imágenes banales, registradas en los medios, aunque algo distanciadas de su significado original, en las que además el cuerpo humano se alza en verdadero protagonista. Y, además, queda fascinado por la interpretación lumínica de unos curiosos reflejos que se desprenden en zonas concretas del lienzo, en un fuerte contraste con la oscuridad de las sombras.

La captación en on de ese mundo alternativo y paralelo, así como su proyección lumínica, se hace mucho más evidente en la última de sus propuestas, la de mayor formato. Las referencias figurativas han desaparecido para dar lugar a una enorme fuente de luz que preside el centro de un formato horizontal. La gama de tonos que desde lo blanquecino va tornado en pigmentos grises, nacarados e incluso verdosos, informan de una todopoderosa presencia central, el nuevo 'dios' de la sociedad de la comunicación. Una tendencia hacia la abstracción que deja de lado por momentos lo figurativo para abrir paso a una autorreferencialidad pictórica inusual, donde los pigmentos del óleo parecen reproducir, con brillos, haces y transparencias, la fuente luminosa, artificial, de la que emanan [2].
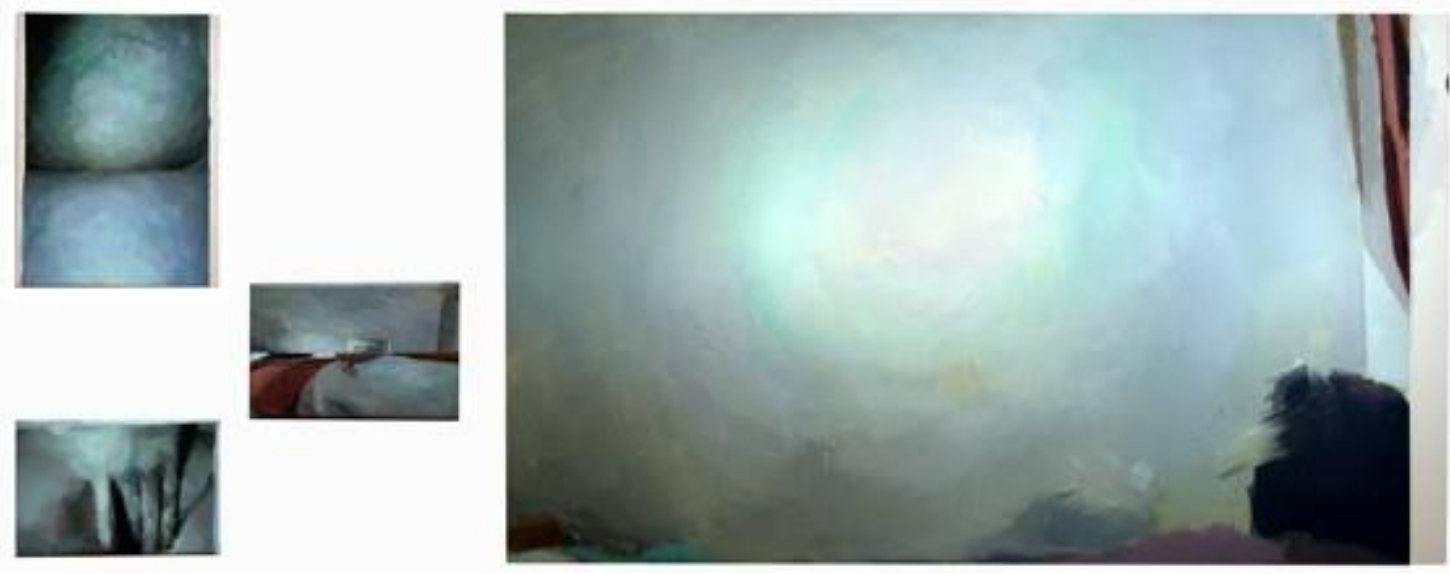

[Fig. 2] Alejandro Martín. Obras sin título pertenecientes a la serie Pintura encendida (2015-2016) 


\section{Conclusiones 'concluyentes'}

Las series de Federico Miró son, desde luego, impactantes, provocando su contemplación un notable goce estético, encauzado a partir de títulos sugestivos. La exquisitez otorgada a su presentación final deviene de ese laborioso procedimiento creativo anteriormente descrito, procurando ofrecer sencillas pistas que ayuden a la comprensión. En esa intención, hay otra mirada mucho más profunda, aquella que es capaz de desbrozar entre la maleza vegetal de sus lienzos las referencias a técnicas desarrolladas por otros conocidos artistas plásticos, así como las intenciones creativas que en torno al arte cinético se advierten en instalaciones y performances. La habilidad está en haber sabido concretar una propuesta distinta, que tiene visos de permanencia y que solo su evolución posterior determinará su validez artística. De momento, el comienzo es esperanzador.

De igual forma, el punto de partida que ofrece Alejandro Martín deberá seguir en un futuro deparando interesantes novedades. De momento, su incipiente carrera ya ha sido objeto de reconocimientos ${ }^{4} \mathrm{si}$ bien será su propia evolución, personal y artística, la que vaya configurando una personalidad distinta en un mundo necesitado de tantos soplos de aire fresco. El reto está en él mismo y en su voluntad de establecer prioridades adecuadas en estas primeras fases de su trayectoria profesional.

\section{Referencias bibliográficas}

GARCERÁ, J. (2009). Take off your shoes, Galería Álvaro Alcázar: Madrid

STEYERL, H. (2014). Los condenados de la pantalla. Caja Negra: Buenos Aires

\footnotetext{
${ }^{4}$ Ha obtenido el Primer premio del festival FanCine, de Málaga (2010) o los segundos del Marbella-Crea y del IX de pintura de la Universidad de Málaga (2015) - y, desde 2013, participando a menudo en exposiciones colectivas celebradas a lo largo del territorio andaluz, con incursiones incluso en el extranjero; significativa entre ellas por la distancia física y su trascendencia, la aportación a Imago mundi, montada por la Fundación Giorgio Cini, en Venecia
} 